Journal of Teacher Education for Sustainability,

vol. 14, no. 2, pp. 54-72, 2012

\title{
ICT-ENABLED CLIMATE CHANGE EDUCATION FOR SUSTAINABLE DEVELOPMENT ACROSS THE SCHOOL CURRICULUM
}

\author{
Vassilios Makrakis, Nikos Larios and Gkolfo Kaliantzi \\ University of Crete, Greece
}

\begin{abstract}
A radical shift in pedagogy is necessary for information and communication technology (ICT) to enhance teaching and learning for sustainability. Climate change takes an inter/crossdisciplinary approach attempting to synthesise diverse ideas and observations concerning global warming. This paper deals with the integration of climate change across the school curriculum through a web-based hypermedia application entitled ICT-enabled integration of climate change education (CCE) that is used as a resource for the EU-funded project ICT-enabled education for sustainable development (ESD). The web-based environment includes interactive activities and supportive material on climate change and is open to all the six forms at the primary school level. The methodological approach used merges ICT, ESD, critical pedagogy and CCE principles and practices. Drupal (content management system) was chosen as the back-end system of our hypermedia learning environment. The main learning content is composed of learning objects (LOs) created through the authoring tool Adobe Flash. The combination of Drupal and Flash provides a dynamic and adaptable learning environment. Through this web-based learning environment that integrates six thematic areas supported by various ICT tools, learners are expected to gain insight into how climate change is altering the planet, potential impacts on the future, and how they can intervene to address its effects.
\end{abstract}

Key words: climate change education, education for sustainable development, curriculum, hypermedia technology, theme-based instruction

\section{Introduction}

In recent years, humankind has faced a profound economic, social and ecological crisis that has its roots in the unsustainable ways people have been treated their environment for years. Sustainable development is generally perceived as an overlapping of four pillars (Figure 1), namely environment, society, culture and economy (UNESCO, 2008). 


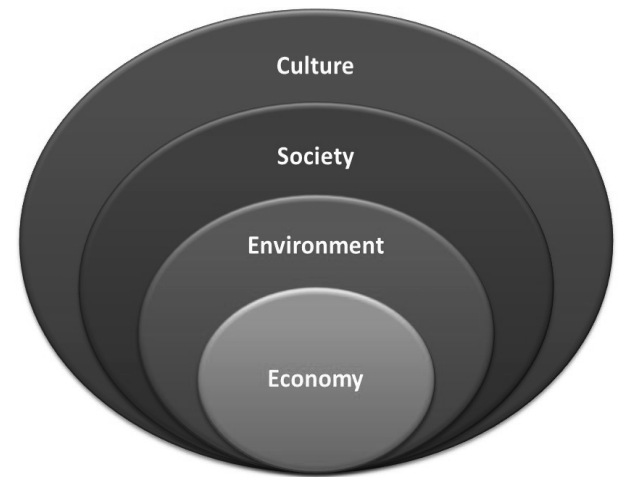

Figure 1. The four pillars of sustainable development

Climate change is currently at the centre of our day to day life as its impacts and consequences are being experienced in all regions of the world. When we talk about climate change, it refers to the alterations in the atmosphere that are over and above natural climate variation and that are a result of human activity. A situation that can be changed if human beings transform their ways of living to be more sustainable and friendly to the environment (Agostino, 2010). Climate change is considered to be the most threatening global environmental problem of our time and has many repercussions not only in the environment, but also in economy, culture and society (UNESCO, 2002, 2010). Article 6 of the United Nations Framework Convention on Climate Change deals with climate change education (CCE), training and public awareness. It has great importance for everybody, especially for young people, working on CCE, awareness raising and training. It also has a great importance for organisations which want to see more young people being part of official government delegations as representatives of the youth in their countries (Youth Non-Governmental Organisation [YOUNGO], 2011).

Although the effects are uncertain, climate change is thought to have implications for arenas including food and water supplies, energy production and use, ecosystem and species survival, human health, social and political stability (Patterson, 1996). It is widely recognised that climate change is having a greater effect on vulnerable populations, groups and communities, this vulnerability being the result of different factors such as age, gender, geography, ethnicity and income group (Agostino, 2010). Despite a large degree of scientific consensus that global warming is occurring, there is less agreement, however, about both the consequences of unchecked global warming and the consequences of strategies to mitigate the negative effects (Houghton, Meira Filho, Callander, Harris, Kattenberg, \& Maskel, 1996). Climate change, in general, has generated considerable scientific and political controversy (Singer \& Seitz, 1998). Education systems everywhere will need to include a focus on the causes, consequences and solutions to climate change if we aspire to changes in people's ways of thinking and living sustainably. Addressing the causes and the consequences of climate change requires a shifting paradigm in content and methodologies in order to build the necessary capacity for mitigation, adaptation and transformation at the personal and societal level. While there was clear 
recognition that professional education for climate change adaptation was limited and urgently needed, it was strongly stated by the professional institutions and their members that it should be integrated with education about and for climate change mitigation as they are complementary and of equal urgency. The study recommends that education about and for climate change adaptation in accredited courses be addressed in an integrated way with education about and for climate change mitigation (Lyth, Nichols, \& Tilbury, 2007).

Recently, climate literacy has received widespread recognition among educators, researchers and education planners recognising the importance of educating children to take a positive stance on social and environmental issues (Shafer, 2008; Stephens \& Graham, 2008; Shafer, James, \& Giuliano, 2009; Dupigny-Giroux, 2010). The National Oceanic and Atmospheric Administration, in cooperation with AAAS and the National Science Foundation (NSF) in the USA defined a climate literate person as able to:

- understand the essential principles of all aspects of the Earth system governing climate patterns;

- know how to assess scientifically credible information about climate;

- communicate about climate change in meaningful ways;

- make scientifically informed and responsible decisions regarding climate and the impact of personal unsustainable actions on climate change (NOAA, 2011).

A climate literate citizen, in other words, should understand the influence of climate on oneself and society and how on can produce positive changes for a sustainable environment. From a teaching and learning perspective, it involves the competences of inquiry-based and problem-based learning. In response to this, CCE is becoming increasingly relevant and a growing number of schools are seeking to embed CCE for sustainable development principles in curriculum planning (Henderson, Steven, \& Holman, 1993; Johnson, Henderson, Gardiner, Russell, Ward, Foster, Meymaris, Hatheway, Carbone, \& Eastburn, 2008; Shepardson, Choi, Niyogi, \& Charusombat, 2009).

The International Alliance of Leading Educational Institutions (2009) has issued eight recommendations for CCE.

1. Climate change makes sustainable development an urgent priority. Thus, policies which promote education for sustainable development (ESD) should play a key part in the negotiation of global agreements on climate change policy.

2. Societies need to change radically consumption, production and behaviour patterns to meet the challenges we face.

3. ESD will make demands on all of society but schools will play a critical role, through what they teach and how they model sustainable practices.

4. Whole-school approaches are promising: societies need to reorient schooling towards a stronger emphasis on interdisciplinary work, participation in authentic sustainability challenges and interaction with others outside school.

5. Universities should offer ESD courses for pre-service and in-service teachers.

6. Resources and time for experimentation are provided and the sustainability is in- 
tegrated into the curriculum.

7. Interaction between researchers, teachers, non-governmental organisations, public officers and others in the field of ESD is essential. Regional Centres of Expertise on ESD, which already exist at some places, may serve as models for this endeavour.

8. ESD research needs to be augmented. It should be focused on 1) documenting the state of practice and identifying promising practices; 2) exploring educational outcomes and their evaluation in respect of ESD and 3) identifying and explaining opportunities and problems of general relevance.

In this paper, we present an example of a Web-based application entitled "Climate change and me" that is one of the six thematic areas of a broader web-based learning environment dealing with CCE across the Greek primary school curriculum. This work has been integrated as a resource in the development of one of the courses in the M.Sc. programme of the ICT-enabled ESD project.

\section{Theoretical background}

\section{The learning paradigm}

The activities developed in this application are based on the principle of ExConTra learning paradigm (Makrakis \& Kostoulas-Makrakis, 2012). As depicted in Figure 2, this model is based on three theoretical approaches to learning: experiential learning, constructivist learning and transformative learning.

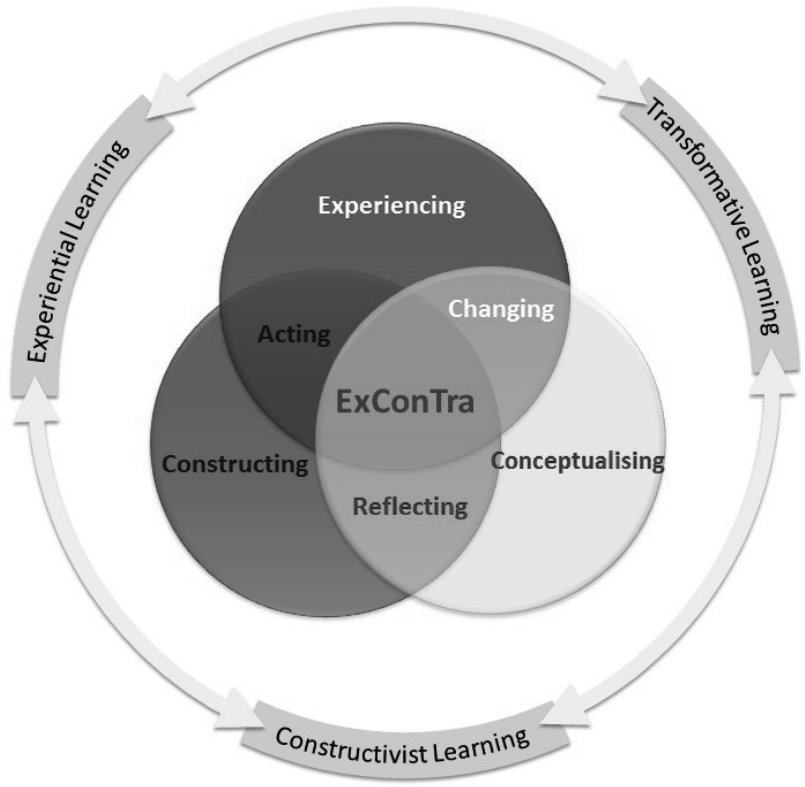

Figure 2. The ExConTra learning paradigm 
Beginning with experiencing, learners identify a realistic and authentic task associated with a sustainable development issue, such as climate change, and start collecting the information needed for their analyses, using various inquiry-based methods. Reducing the production of greenhouse gasses and in preparing societies for adaptability to risk and physical environmental change, CCE needs to be experienced-based and practice-centred. Learning-centred actions for changing unsustainable practices are needed (for instance, learning to implement energy saving measures), so that learners can experience and reflexively review their values and practices in climate change solutions. Through reflecting, self and/or social, as well as through further reading and observing, learners organise and examine the collected data for the new experience from multiple perspectives in order to find meaning. For learners to make meaning, either individually and/or shared, they need to reflect on their own experiences, leading them to develop more abstract understandings of their experiences (conceptualising). Arriving at individual and shared meaning (constructing), learners need to get involved in a shared inquiry enriched through continuous reflection, reconceptualisation and active experimentation. In this sense, learning is an active and contextualised process of constructing meaningful knowledge based on own experiences, rather than acquiring it from someone else. Constructed knowledge and meaning is meaningful when it opens up opportunities for action. Merging knowledge and meaning with action (acting) implies a change agency and active citizenship. Acting as change agents, learners are empowered to transforming experience through critical reflection and active experimentation. When critical reflection is transformed into an action, it becomes praxis that turns learners able to transform oneself and society (transforming).

Central to the climate change processes of mitigation, adaptation and transformation are new values, creative thinking and problem-solving skills. These skills require learners to engage in critical analysis of causes and consequences and construct knowledge that may lead to action. This requires teachers involved in CCE to integrate into their teaching and learning methodologies experiential, constructivist and transformative learning principles and values. Teachers need to shift from functioning as the sole source of information to becoming co-learners and facilitators using multiple sources of information and provide support and motivation in helping learners in the process of self-directed learning. Similarly, students' roles also need to change from passive recipients of climate change information to active learners who search, collect, analyse and interpret climate change data and collectively build up knowledge through inquiry and reflection.

\section{The curriculum paradigm}

Simply introducing new content about climate change, its causes, consequences and solutions will not be an adequate response to CCE. A horizontal approach instead of a vertical is needed for curriculum planning. Such an approach to climate change curriculum planning describes how knowledge and skills related to climate change are clustered around areas or sub-themes (Makrakis, 2012). It is assumed that the integrated horizontal approach: 1) cross- 
fertilises knowledge within and between school subjects and encourages a holistic view of climate change issues; 2) enables students to situate their learning in meaningful contexts; 3 ) encourages the development of higher-level thinking skills and the exploration of inter/crossdisciplinary questions and issues and 4) promotes team teaching and collaboration among teachers of different school subjects and collaborative learning among students. Thematic instruction can thus be a critical tool for reintegrating the curriculum and eliminating the reductionist nature of well-structured problems that have convergent solutions in contrast of ill-structured problems that favour divergent modes of thinking. Ill-structured problems are more suitable to thematic instruction, and, as pointed by Jonassen (1997), learning from ill-structured problems, students engage in a reflective conversation in a dialectical way. They are required to conceptualise the problem, recognise the divergent perspectives and multiple representations of the problem, determine what information and skills are needed to solve the problem and synthesise their understanding of the problem. In doing this, Jonassen (1997) claims that they have to: (a) articulate the problem space and contextual constraints; (b) identify and clarify alternative opinions, positions and perspectives of stakeholders; (c) generate possible solutions; (d) assess the viability of alternative solutions by constructing arguments and articulating personal beliefs; (e) monitor the problem space and solution options; (f) implement and monitor the solution and (g) adapt the solution.

Cunningham and Billingsley (2003) identified a list of guidelines that we think can be used to enable a thematic approach to CCE curriculum.

- Plan authentic activities. Select activities that are similar to activities that students might encounter in life outside of school.

- Promote self-directed learners. Design activities that encourage learners to manage their own learning by allowing them to make choices about their use of time, topics or subject matter and possibly criteria for successful learning.

- Go beyond one subject area. Create activities that encourage the exploration of cross disciplinary questions and issues.

- Use multiple approaches. Plan a diverse range of activities and allow students to choose what kind of activity they believe will work best for them.

- Go beyond retelling. Include activities that require the use of higher-level thinking skills such as compilation, solving a mystery, designing a product or plan, building consensus, persuading, seeking self-knowledge or making judgments.

- Keep it simple. Both teachers and students find simpler curriculum designs easier to use.

- Borrow activity ideas from others. Take advantage of the wonderful educational resources that are available on the web and do not feel like you have to create the materials for every technology-based learning activity yourself.

- Touch imagination. Give students opportunities to use their imaginations for wonder, creativity or self-expression.

- Build to promote intentionality. Student learning activities should be designed and 
conducted with clear purposes that will help to achieve learning goals.

- Engage the learner. Design interesting activities that require learner participation and that will challenge the learner's current skills, knowledge and attitudes.

- Build on controversy. Build learning activities around controversial issues and offer students opportunities for accessing and comparing different views on these topics.

- Use characteristics of the web. Make use of web elements such as hypertext, multimedia, communication tools and interactivity.

- Build activities around current events. Design activities that include opportunities to learn about current events.

- Use non-web materials, events and locations. Use the internet for some things, but not for everything.

- Facilitate spontaneity and discovery. Strive to find the proper balance between teacher control and student freedom.

- Plan for open-ended inquiry. Let students make choices within a set of educationally sound boundaries.

All these guidelines point to the notion of a recursive curriculum that finds its foundations in ExConTra learning theories. The rationale for teaching climate change thematically addresses situated learning within a context that is more meaningful to learners than traditional or linear approaches to instruction. Meaningful learning requires knowledge to be constructed by the learner, not transmitted from the teacher to the student (Jonassen, Peck, \& Wilson, 1998). The teaching of climate change thematically is aligned to the realm of ExConTra learning because the content is embedded in sub-themes that serve as learning contexts for experiencing, constructing and transforming knowledge with action for change. The following description introduces the function of this Web-based learning platform for each stage of thematic learning (Figure 3).

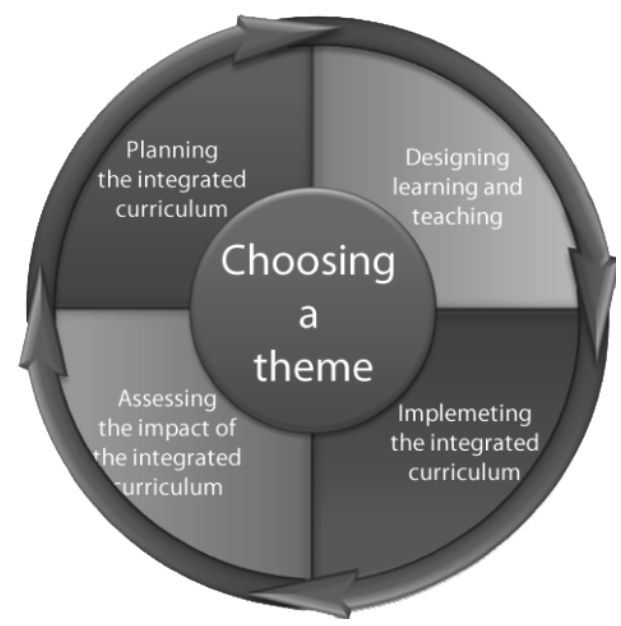

Figure 3. Steps in designing a theme-based instruction 
Choosing a theme. This stage involves the choice of a large theme related to a compelling reallife issue, such as climate change which has meaningful connections in the broader framework of human experience that may connect family, school and community. In a recent study, it has found that web-based thematic learning has positive effects on learners' concept learning, provides learners with a framework from which develop the related concepts in a more stable learning mode and which is suitable for students with different abilities (Liu \& Wang, 2010).

Planning the integrated curriculum. In this stage, sub-themes, in the form of thematic areas, such as "Climate change and me", are planned to integrate concepts, skills and strategies that give meaning and direction to the whole learning process of climate change. The teachers involved organise the climate change core curriculum (both process skills and content knowledge) and sub-themes in an open and flexible way to assure students' involvement at a later stage. Inter/cross disciplinary approaches are adopted in planning the integrated curriculum giving more emphasis to the processes involved rather than the outcomes. In web-based settings, a particular emphasis is given to a variety of interaction choices for participants: teacher-to-student, student-to-student and student-to-resources and content. Additionally, a well-planned curriculum balances three types of activities: individual, small and large group activities. By ensuring multiple channels of communication, engagement and collaboration within the design of a curriculum, providing a richly textured environment that can accommodate a full range of students' needs and learning styles, are of critical importance (Boettcher, 2007).

Designing learning and instruction. In a web-based learning environment, the learner interacts with the content, teacher and technology. This stage involves, first, the design of learning activities enabled by information and communication technology (ICT). Through designing learning activities suitable for web-based learning environments and driven by the ExConTra learning, the content becomes the means to an end and not an end in itself. In designing thematic learning and instruction, one approach that is consistent with the ExConTra learning principles is that a group of teachers can brainstorm learning activities using existing curriculum materials and draw directly from end-users' (teachers and students) ideas, interests and experiences during the formative evaluation process. In this process, involving community experts and other members could add value to designing meaningful and engaging learning activities. Strategies that ensure the reusability, adaptability and generalisability of teaching and learning materials should be planned.

Implementing the integrated curriculum. As pointed earlier, one of the most effective strategies for an integrated theme-based curriculum approach is to teach the subject climate change in conjunction with other subjects. This allows students to make connections between different areas as they explore a topic in detail and from a variety of approaches. Cross-curriculum projects allow students to see how knowledge and skills are connected in the various school subjects and how the knowledge constructed and the skills acquired can be transferred to other situations and real-life contexts. This step involves project-based learning as a model for implementing thematic learning activities. It is a shift away from the traditional classroom 
practices of short, isolated, teacher-centred lessons. Instead, it emphasises learning activities that are long-term, interdisciplinary, student-centred and integrated with real-world issues and practices in which students plan, implement and evaluate projects that have real-world applications beyond the classroom. ICT should be involved in such a curriculum in two ways. Firstly, technology can be used to support the instructional process, and, secondly, it should be a significant part of the content of the curriculum. The theme should provide a context for learning with ICT and vice versa. Various ICT tools and Venn diagrams, such as concept maps and semantic webs, help show the connection between related concepts and help learners explore meaningful learning experiences. Implementing the integrated curriculum in web-based learning settings with different tools and resources for retrieving content, using the online tools and facilitating interactions among teachers and students as well as other stakeholders, requires new instructional practices, such as peer tutoring and collaborative learning.

Assessing the impact of the integrated curriculum. In this stage, the information collected from evaluating a curriculum forms the basis for making judgements about how successfully has the programme achieved its intended outcomes and the worth or value of the programme. This process can be integrated into three interlinked assessment levels: 1) diagnostic; 2) formative and 3) summative. The term diagnostic refers to a process at the initial phase; the term formative refers to a process while developing the curriculum so that revisions to it can be made, and the term summative refers to a process at the end/after the curriculum programme is implemented. A critical concept applied to these processes is authentic assessment that is driven by ExConTra learning foundations. Authentic assessment to be incorporated in assessing the impact of the integrated curriculum include an amalgamation of tools and strategies that derive from ExConTra learning but also from objectivist learning theories if such tools contribute to the ExConTra learning principles. The most used tools include: multiple choice tests with extended responses to help students become aware of their own thinking processes, observation, checklists, portfolios, concept mapping, Venn diagrams, scenario building, reflection, reflexivity, journalising, simulation, case-study analysis. All the three levels of assessment are interlinked, and, in a way, they provide a holistic framework for assessment. However, we consider formative assessment as the most critical process as it provides effective feedback and gives the opportunity for learners' and other stakeholders' active participation in the design and development of the integrated curriculum. Within this process, the use of concept maps and other structural knowledge representation techniques are very effective tools (Åhlberg, 2004; Trumpowe \& Shahzad Sarwar, 2010). The process of formative assessment should enable students to self-monitoring progress, give regular feedback to students, support peer learning and assessment and design self assessment practice (Liang \& Kim, 2004). Visualisation tools, such as conceptual maps, help students process the abstract concepts or mental images that they depict, and the more they work designing materials, the more they construct their own meaningful realities based on new knowledge (Jonassen \& Reeves, 1996; Jonassen et al., 1998). 
A well-planned programme of CCE across and within the curriculum will provide pupils with opportunities to address the causes (mitigation) and the consequences (adaptation) of climate change by adopting a transformative learning approach. As the causes of climate change are basically anthropogenic, causes and consequences need to be identified and changed. Locally relevant solutions and adaptation practices are also needed, alongside efforts to share and transfer knowledge, social strategies, economic models and technologies that provide new solutions across the world. Practically, this necessitates learning processes and methods that turn learners of all ages able to reduce energy consumption, use renewable forms of energy and change consumption patterns. At a societal and cultural level, this means changes in social, cultural and economy structures that are part of the problem. There is a need for a new paradigm in teaching and learning as well as in curriculum that will transform unsustainable values and practices that dominated in the 20th century. CCE requires people everywhere to understand and respond to the nature, causes and consequences of climate change. This requires CCE for sustainable development (see www.unesco.org/desd) programmes that attend to:

- clear distinctions between different scientific concepts and processes associated with climate change;

- knowledge and abilities to distinguish between certainties, uncertainties, projections and risks associated with climate change;

- knowledge of the history and interrelated causes of climate change;

- knowledge of mitigation and adaptation practices that can contribute to wider social transformation towards sustainability, including abilities to participate in such practices;

- knowledge of consequences and what is being learned about mitigation and adaptation to climate change;

- good understanding of the time-space dynamics of climate change, including the delayed consequences that current greenhouse gas emissions hold in store for the quality of life, security and development options of future generations;

- understanding of different interests that shape different responses to climate change (for instance, business interests, consumer interests, farmers' interests, political interests, future generations' interests, etc.) and abilities to critically judge the validity of these interests in relation to the public good;

- critical media literacy to address the causes of over-consumption and develop capacity to make better lifestyle choices and to participate in climate change solutions.

\section{ICT as enabling tools for CCE}

The link between ICT and sustainable development is being addressed by extensive debates and research which recognise the challenge new technologies bring to the reorientation of 
education towards learning to live sustainably (Makrakis, 2006; Makrakis, 2010abc; Makrakis, 2011). ICT-enabled CCE for sustainable development may help children to understand better climate change and motivate them to get engaged in actions to prevent it. ICT is interlinked with climate change in various ways. They are most obviously used for data analysis and prediction, access to relevant information and raising awareness at the grassroots level. ICT can also facilitate learning and practical knowledge, while empowering the poor and marginalised to raise their voice for their rights. Many educators believe in the immense potential of ICT as enabling learning tools. However, to realise the potential of ICT and geospatial technologies as enabling tools for teaching and learning in general and in particular concerning climate change, we have to reconsider what we teach as well as how we teach, but most of all it is necessary to revise our understanding of how people learn. Geographic information system (GIS) is a set of technologies which allow users to view, understand, question, interpret and visualise spatial data in many ways that reveal relationships, patterns and trends in various form. It helps enhance spatial reasoning and support problem solving in the classroom. In addition, the proper implementation of GIS instruction may promote climate change literacy and inter/cross disciplinary learning in the classroom. In general, GIS offers a powerful decision-making toolkit that helps students understand content in a variety of disciplines, such as geography, mathematics, social studies, history, language arts, environmental studies, chemistry, biology, civics. The internet also offers many outstanding resources on climate change that can be assessed and used to support CCE in the classroom.

In developing the web-based learning for CCE, Drupal was chosen as the back-end system of our hypermedia learning environment. Drupal is a free open source content management system (CMS) written in PHP (Hypertext PreProcessor) and distributed under the GNU General Public License. Some key advantages offered by CMS solutions are low development time along with a high reliability and a wide variety of useful tools for educators such forums, wikis, blogs, quizzes, polls, sweepstakes and many other robust social networking modules. The main learning content is composed of learning objects (LOs). LOs are digital pieces of learning content that may comprise text, images, hyperlinks and also audio, video clip or animation as well as web pages. LOs can be produced, re-used, modified observing the copyrights (Wiley, 2000, 2011). Each LO is constructed from various media assets, such as text, video, animation, charts and sound narration all gathered under a simple graphic user interface (Schreurs, Dalle, \& Sammour, 2009). The authoring tool that was used to create and modify LOs used and reused in our web-based learning environment is Adobe Flash. The combination of Drupal and Flash provides a dynamic and adaptable learning environment. Moreover, the learning environment is enriched through the integration of various ICT tools, such as concept maps (Text2Mindmap), spreadsheets (Zoho Sheet), presentations, paint tools (Pixlr), word processing (Zoho Writer) and a modern Greek online dictionary. Any supplementary material needed include relative web pages, web articles, case studies, videos, animations, general ideas or advice and help for teachers and students. There is also a glossary including difficult terms. Students search the web and create their own material engaging with 
the suggested activities and save it through an electronic portfolio. They can also create pages, comments, blogs and forums, send emails and be directly connected through social networks.

\section{Structuring the learning content across the curriculum}

As pointed earlier, the "Climate change and me" is one of the six key areas of the web-based learning environment targeted to primary school curriculum from forms 1 to 6 (Figure 4).

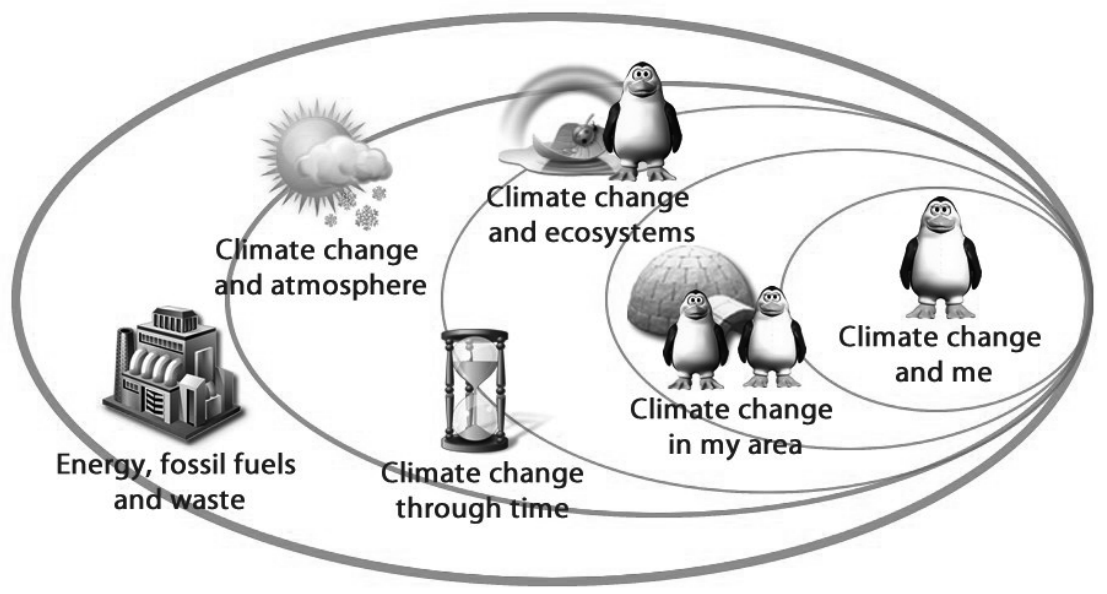

Figure 4. The curriculum areas of the ICT-enabled CCE

In the area "Climate change and me" children investigate about what climate change has to do with them (their school, family, nutrition, health, etc.) and what they can do in their everyday life (in school, home, neighborhood, local area) to face climate change using the media, the internet, arts and sports. Then, children can move to the area "Climate change in my area" and investigate how climate change can affect their local society and economy, the employment, the transportation, etc. The next area, "Climate change and ecosystems", gives children the opportunity to explore their local and national ecosystem and the repercussions climate change brings upon it. In the next area, "Climate change and atmosphere", children learn about the physics of the phenomenon of climate change in the atmosphere. The following area, "Climate change through time", gives children the opportunity to learn about climate change in the past, in the present and in the future. They study scenarios and prepare themselves for the future, having the knowledge from the past. Finally, in the area "Energy, fossil fuels and waste", children investigate what climate change has to do with energy, fossil fuels and waste. They search for ways to make a sustainable future, using renewable sources of energy and new ways to handle waste. Students can choose any of these units to start with and engage to its activities. In these units, children deal with what climate change brings upon them and their local environment and how children can act in order to protect their environment. Alongside 
the activities conducted in the classroom, many activities outside the classroom are suggested, referring gradually from the local to national and global level (Figure 5).

The learning activities are written with the developmental needs of the learners in mind, recognising that adaptations will be necessary depending on their characteristics and circumstances. This curriculum is intended to be flexible, allowing the teacher to select some or all of the activities in order to develop their own learning activities together with his/her learners. We also tried to develop learning contents in the form of units that are not dependent on previous units. Thus, the units and activities may be implemented either sequentially and/or according to the existing curriculum organisation of content and needs.

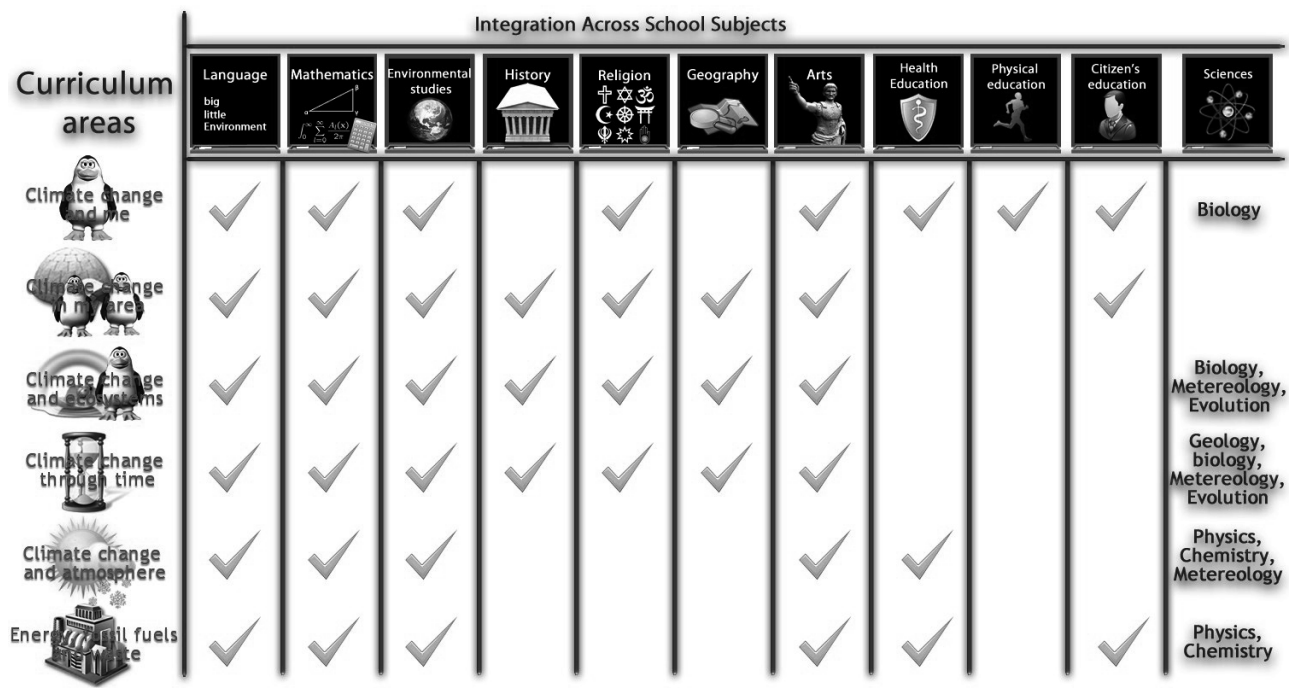

Figure 5. The cross-disciplinary structure of the ICT-enabled CCE curriculum

The structure of the area "Climate change and me" as in any of the rest areas is based on three levels: Form 1-2 (6-7 year olds), Form 3-4 (8-9 year olds) and Form 5-6 (10-11 year olds).

\section{Form 1-2 level units}

1. Me, the child. Students discover how climate change can affect children all over the world through a case study and a video. Then, they take action to help children that are affected by climate change either by establishing collaboration with relevant organisations or by acting appropriately in their ordinary lives.

2. My house and my school. Children investigate which daily behaviors either in their school or in their house connect with and deteriorate climate change. Then, they act in order to make their school and their house friendly towards the environment.

3. Our nutrition. Children discover how climate change can affect the quality and quantity of food. They also learn what they should eat according to a healthy diet 
and which food choices can affect climate change. In the end, they act in order to help children that are hungry because of climate change's repercussions in agriculture.

4. Sports and health. Children learn that a healthy organism in a good physical shape is more prepared for climate change consequences in health and nutrition. Then, they organise athletic events to promote their fight against climate change.

\section{Form 3-4 level units}

1. Media, the internet and climate change. Children find out how climate change is presented in the media and the internet. Then, they gather and evaluate information about climate change in the media and the internet. They also learn about the hazards of the use of the internet. In the end, they use the media and the internet in order to promote their actions regarding their fight against climate change.

2. Climate change and arts. Children learn new ways to express themselves and send messages about climate change through arts. They use recycled materials to create art. Children also post and promote their art in electronic galleries. In the end, they attempt to create a new art wave to move people about climate change.

3. How to help each other. Children take action in order to help other children in their country or in other countries fight starvation and poverty. They also create and organise a social group of people that will help one another according to their abilities.

4. Consumerism and climate change. Children become aware of how they decide to buy goods. Then, they learn about fait trade and how to reinforce the local market and the local goods in order to fight climate change. In the end, they seek ways to resist consumerism.

\section{Form 5-6 level units}

1. Social impact of climate change. Children discover about the social consequences of climate change, such as the lack of food and water, the need to emigrate and the deterioration of human health. Then, they make a relevant presentation for smaller children and generally motivate others to engage in actions against the social consequences of climate change.

2. Politics, economy and climate change. Children find out the role of politics and economy in the climate change issue. They learn about the economic repercussions of climate change in their country and abroad. They also discover how politicians make decisions according to their economic interest. Then, they investigate how climate change is related to the world financial crisis. In the end, they try to act organising a school conference where children take decisions about climate change in the future. 
3. Disease and climate change. Children learn about the diseases that climate change can bring upon humans through articles and case studies. Then, they study how health security systems will be affected in poor and rich countries. In the end, they seek measures to alleviate people affected and ways to inform others about climate change and disease.

4. Family, emigration and climate change. Children explore how climate change can make people emigrate. They learn about environmental emigration and environmental refugees. They also seek ways to help emigrants who moved because of climate change.

5. Climate change caused by human activity. Children investigate if and how human activity contribute in global warming and cause climate change, studying diagrams, relative articles and interviews by scientists. They also evaluate the opposite view (that climate change is not caused by human activity) and debate about it.

\section{Concluding remarks}

Climate change is a global issue. Addressing it is a shared responsibility. Yet, it is increasingly apparent that failure to act will render the environments of millions of people and their families at a high risk. This paper deals with the integration of climate change in school curriculum through a web-based inter/cross disciplinary hypermedia application entitled "ICT-enabled climate change education". In particular, this paper explores the "Climate change and me" which is one of the six areas of this application. The web-based environment developed includes interactive activities and supportive material regarding the information, the changing of attitudes and actions on climate change and is open to all primary school forms. The methodological approach used is based on ExConTra learning paradigm that integrates critical pedagogy, critical constructivism, ESD and hypermedia technology. The activities are based on authentic learning situations, experiences and problems that may be encountered by students in their daily life, about what may happen to them and their family due to climate change and what they can do to change it. The main tools used in the activities are conceptual maps, text editors, spreadsheets, painting tools, discussion forum, etc. Children are engaged in real-life problems, studying stories, case studies, websites, articles or videos and developing activities using various tools and digital learning objects. A critical driver behind this web-based learning environment for CCE is the availability of open, flexible, e-learning opportunities and affordable ICT that enable time- and place-independent learning. By providing opportunities for enabling CCE through ICT in which learners are allowed and expected to develop their knowledge and understanding, the shift to transformative learning seems to become easier. To conclude, ICT is used in this web-based environment as a cognitive tool and opens students opportunities to merge theory with praxis. 


\section{Acknowledgement:}

This work has been developed within the framework of the ICTeESD project that has been funded from the European Commission (ERASMUS Multilateral Programme Virtual Campus Project No. 510212-LLP-1-2010-1-GR-ERASMUS-EVC (2010-3494). The content of the paper reflects the views of the authors, and the Commission cannot be held responsible for any use which may be made of the information contained therein.

\section{References:}

Åhlberg, M. (2004). Concept mapping for sustainable development. In A. J. Cañas, J. D. Novak \& F. M. González (Eds.), Concept maps: Theory, methodology, technology. Proceedings of the First International Conference on Concept Mapping. Retrieved August 19, 2012, from http://cmc.ihmc.us/papers/cmc2004-233.pdf

Agostino, A. (2010). Gender equality, climate change and education for sustainability. Newsletter for beyond access: Gender, education and development, 24. Retrieved August 12, 2012, from http://www.e4conference.org/wp-content/uploads/2010/02/Equals24.pdf

Boettcher, J. (2007). Ten core principles for designing effective learning environments: Insights from brain research and pedagogical theory. Innovate, 3(3). Retrieved August 16, 2012, from http://www.innovateonline.info/index.php?view=article\&id=54

Cunningham, C., \& Billingsley, M. (2003). Curriculum webs: A practical guide to weaving the web into teaching and learning. Boston: Allyn \& Bacon.

Dupigny-Giroux, L. A. (2010). Exploring the challenges of climate science literacy: Lessons from students, teachers and lifelong learners. Geography Compass, 4(9), 1203-1217.

Henderson, S., Steven R., \& Holman, S. (1993). Global climate change education: Technology transfer to schools. Climate Research, 3, 137-140.

Houghton, J. T., Meira Filho, L. G., Callander, B. A., Harris, N., Kattenberg, A., \& Maskel, K. (1996). Climate change 1995: The science of climate change. Cambridge: Cambridge University Press.

IALEI (International Alliance of Leading Education Institutes). (2009). Climate change and sustainable development: The response from education. Retrieved September 10, 2012, from http://www.intlalliance.org/fileadmin/user_upload/documents/DPU_recommendations. pdf

Johnson, R. M., Henderson, S., Gardiner, L., Russell, R., Ward, D., Foster, S., Meymaris, K., Hatheway, B., Carbone, L., \& Eastburn, T. (2008). Lessons learned through our climate change professional development program for middle and high school teachers. Physical Geography, 29, 500-511.

Jonassen, D. H. (1997). Instructional design models for well-structured and ill-structured problem-solving learning outcomes. Educational Technology: Research and Development, 
45(1), 65-95.

Jonassen, D. H., \& Reeves, T. C. (1996). Learning with technology: Using computers as cognitive tools. In D. H. Jonassen (Ed.), Handbook of research for educational communications and technology (pp. 693-719). New York: Macmillan.

Jonassen, D. H., Peck, K. L., \& Wilson, B. G. (1998). Learning with technology: A constructivist perspective. Columbus, $\mathrm{OH}$ : Prentice-Hall.

Liang, X., \& Kim, C. (2004). Classroom assessment in web-based institutional environment: instructors' experiences. Practical Assessment, Research \& Evaluation, 9(7). Retrieved August 12, 2012, from http://PAREonline.net/getvn.asp?v=9\&n=7

Liu, M. C., \& Wang, J. Y. (2010). Investigating knowledge integration in web-based thematic learning using concept mapping assessment. Educational Technology \& Society, 13(2), 25-39.

Lyth, A., Nichols, S., \& Tilbury, D. (2007). Shifting towards sustainability: Education for climate change adaptation in the built environment sector. A report prepared by the Australian Research Institute in Education for Sustainability. Retrieved September 15, 2012, from http://aries.mq.edu.au/projects/ClimateChange/files/climateChange.pdf

Makrakis, V. (2006). Preparing United Arab Emirates teachers for building a sustainable society. University of Crete: E-Media publications.

Makrakis, V. (2010a). ICT-enabled reorienting teacher education to address sustainable development: A case study. In T. Jimogiannis (Ed.), Proceedings of the 7th Panhellenic Conference ICT in Edication (pp. 1-8). Korinthos: University of Peloponnese.

Makrakis, V. (2010b). Strategies to reinforce the role of ICT in teaching and learning for sustainability. In M. Witthaus, K. Candless \& R. Lambert (Ed.), Tomorrow today (pp. 169171). Leicester: Tudor Rose \& UNESCO.

Makrakis, V. (2010c). The challenge of WikiQuESD as an environment for constructing knowledge in teaching and learning for sustainable development. Discourse and Communication for Sustainable Education, 1(1), 50-57.

Makrakis, V. (2011). ICT-enabled education for sustainable development: Merging theory with praxis. In M. Youseef \& S. A. Anwar (Eds.), Proceedings of the 4th Annual Conference on e-Learning Excellence in the Middle East - in Search of New Paradigms for Re-engineering Education (pp. 223-232). Dubai: Hamdan Bin Mohammed e-University.

Makrakis, V. (2012). Critical issues for the course curricular design and development of post-graduate programmes. Proceedings of the International Forum "Modern Information Society Formation - Problems, Perspectives, Innovation Approaches" (pp. 85-107). Saint Petersburg: State University of Aerospace Instrumentation.

Makrakis, V., \& Kostoulas-Makrakis, N. (2012). The challenges of ICTs to online climate change education for sustainable development: The ExConTra learning paradigm. In S. A. Anwar (Ed.), Proceedings of the 5th Conference on eLearning Excellence in the Middle East 
- Sustainable Innovation in Education (pp. 594-605). Dubai: Hamdan Bin Mohammed e-University.

NOAA (National Oceanic and Atmospheric Administration). (2011). Increasing public demand for NOAA'S climate-related data and services. United States Department of commerse: NOAA. Retrieved October 28, 2012, from http://www.noaa.gov/climate.html.

Patterson, C. H. (1996). Multicultural counseling: From diversity to universality. Journal of Counseling and Development, 74, 227-231. DOI: 10.1002/j.1556-6676.1996.tb01856.x.

Singer, F. S., \& Seitz, F. (1998). Hot talk, cold science: Global warming's unfinished debate. Washington DC: The Independent Institute.

Shafer, M. A. (2008). Climate literacy and a national climate service. Physical Geography, 29, 561-574. DOI: 10.2747/0272-3646.29.6.561.

Shepardson, D. P., Choi, S., Niyogi, D., \& Charusombat, U. (2009). Seventh grade students' mental models of the greenhouse effect. Environmental Education Research, 15(5), 549570. DOI: $10.1080 / 13504620903564549$.

Schreurs, J., Dalle, R., \& Sammour, G. (2009). Authoring systems delivering reusable learning objects. International Journal of Emerging Technologies in Learning, 4(2), 37-42. DOI: $10.3991 /$ ijet.v4s2.812.

Stephens, J. C., \& Graham, A. C. (2008). Climate science to citizen action: Energizing nonformal climate science education. EOS, Transactions American Geophysical Union, 89(22), 204-205. DOI: 10.1029/2008EO220010.

Trumpowe, D., \& Shahzad Sarwar, G. (2010). Concept maps: Making learning meaningful. In A. J. Sánchez, A. J. Cañas \& J. D. Novak (Eds.), Formative structural assessment: Using concept maps as assessment for learning. Proceedings of the 4th International Conference on Concept Mapping (pp. 132-136). Chile: Lom Ediciones S.A. Publisher.

UNESCO (United Nations Educational, Scientific and Cultural Organisation). (2002). Unesco universal declaration on cultural diversity. Paris: UNESCO.

UNESCO (United Nations Educational, Scientific and Cultural Organisation). (2008). Culture and sustainable development: Executive summary. Netherlands: National Commission for UNESCO.

UNESCO (United Nations Educational, Scientific and Cultural Organisation). (2010). The UNESCO climate change initiative: Climate change education for sustainable development. Retrieved September 14, 2012, from http://unesdoc.unesco.org/ images/0019/001901/190101e.pdf

Wiley, D. A. (2000). Connecting learning objects to instructional design theory: A definition, a metaphor, and a taxonomy. In D. A. Wiley (Ed.), The instructional use of learning objects (pp. 1-35). Bloomington: Association for Instructional Technology and Association for Educational Communications and Technology.

Wiley, D. A. (2011). Learning objects, content management, and e-learning. In N. F. Ferrer 
\& J. M. Alonso (Eds.), Content management for e-learning (Part I, pp. 43-54). New York: Springer.

YOUNGO (Youth Non-Governmental Organisation). (2011). Enhanced youth participation and education. In climate change: The Article 6 implementation toolkit. A collaborative document created by international youth. Retrieved September 14, 2012, from the YOUNGO Article 6 Working Group http://unfccc.int/cc_inet/files/cc_inet/information_ pool/application/pdf/enhanced_youth_participation.pdf

\section{Correspondence:}

Vassilios Makrakis, Professor of ICT in Education, University of Crete, Department of Primary Education. Email: makrakis@edc.uoc.gr 